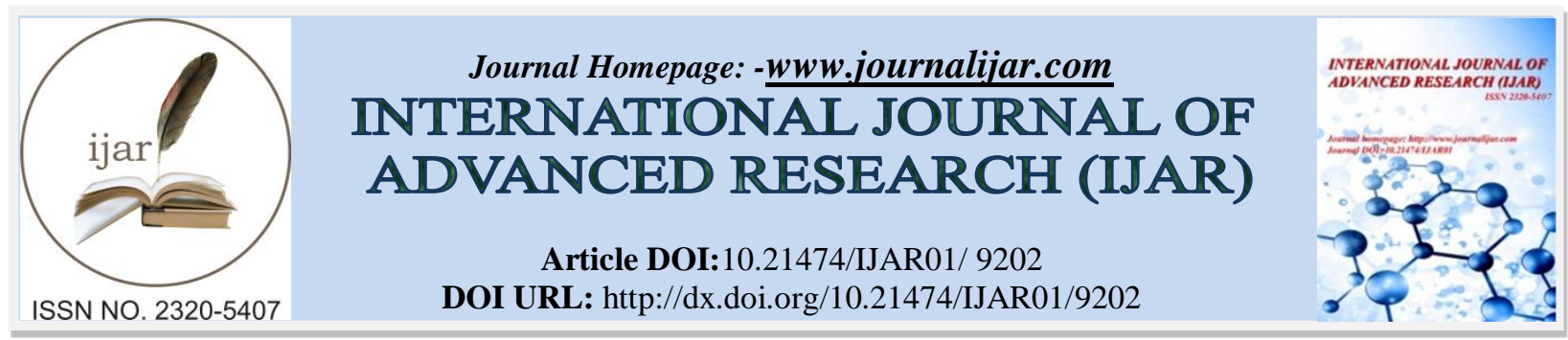

RESEARCH ARTICLE

\title{
AN ASSESSMENT OF VOLATILITY TRANSMISSION IN THE PAKISTAN, INDIA AND SRI LANKA STOCK MARKETS USING BEKK-GARCH MODEL.
}

Samreen Fatima and MudassirUddin.

\section{Manuscript Info}

Manuscript History

Received: 04 April 2019

Final Accepted: 06 May 2019

Published: June 2019

Key words:-

Volatility, Spillovers, BEKK-GARCH.

\begin{abstract}
This paper inspects the dynamics of volatility and volatility comovement among Pakistan (KSE-100), India (BSESN) and Sri Lanka (CSE) stocks markets. The volatility and cross-volatility are modeled via BEKK-GARCH model using daily returns indices of the selected stock markets from January, 2011 to January, 2019. Empirical analysis reveals that BEKK-GARCH $(1,1)$ model is found to be appropriate as it has less number of parameters (parsimony). The value of GARCH parameter is high in BSESN which indicates that Indian stock market is highly persistent. This shows that if shocks occur it will take a long time to die out from the market dilemma. However, the coefficient of GARCH has minimum value in KSE-100 among all. On the other hand, the value of short run shock (ARCH coefficient) is high in CSE. This suggests that volatility is more sensitive to past market events for a short period of time. The strongest cross-market effect is detected between India and Sri Lanka. On the contrary, the volatility comovement is high between Pakistan and Sri Lanka.
\end{abstract}

Copy Right, IJAR, 2019,. All rights reserved.

\section{Introduction:-}

Over the past few decades, modeling multivariate volatility has attracted a considerable interest in the field of financial application. Individual and institutional investors are not only interested to invest in their own market but also want to invest in another countries market. They are more curious to understand the behaviors of markets which give higher returns with low risk levels. Investors may leave a securities exchange that is highly fluctuated. They move their reserves from stocks as per the level of volatility co-movement between market places. However, investor and institutional stakeholder accepted a desirable level of volatility. If the volatility is highly correlated across markets stakeholder tend to scan for relative autonomous resources keeping in mind the end goal to maintain the ideal portfolio determination.

Last two decades trade and monetary development has improved the procedure of globalization, with expanded exchange links and financial organization, universal securities exchange lists have become integrated. A country allows outsiders to purchase the stock in that country's securities exchange is called stock exchange liberalization [1]. This monetary liberalization reinforces the development and steadiness of economic growth. The stock markets which are enormously cointegrated propose that there are no diversification assistances subsequently the performance and returns in these markets are highly correlated to each other. 
There is abundant literature explore volatility linkages between the markets ([2]-[3]). [4] used multivariate GARCH process to analyzing the linkage among the local markets of Jamaica, Trinidad, Barbaros and NYSE. In another paper, volatility co-movement among the India, Singapore and Hong Kong markets were studied via multivariate GARCH by [5]. Their result indicated that the India, Singapore and Hong Kong markets are assimilated effectively. [6] inspected linkage between US and European stock markets namely; CAC, DAX, FTSE100 and S\&P 500 using multivariate frame work, BEKK and DCC models. Their result depicted that UK is the main source of transmitting volatility within the European markets. On contrary, US market may also transmit volatility among the European and within the US stock markets. In addition to this, European markets are more interdependent which is to be confirmed via unconditional /conditional correlation. [7] applied various volatility models for univariate (GARCH) and multivariate volatility (BEKK) models to investigate volatility in Polish economy. Eleven possible univariate models were addressed to capture various structures of volatility. Their findings showed that ARIMA-GARCH model was able to capture the dynamic of volatilities of the Polish economy.

Kumar , used [9] method to study the co-movement between exchange rates and stock prices for India, Brazil, South Africa [8]. He used VAR-BEKK model and found a bi-directional volatility spillover effect amongst the stock returns. In another paper, [10] investigated the co-movement between the Indian and US Stock Markets for daily price data covering from January 2012 to April 2014. A bidirectional volatility spillover effect among the markets was found and also the impact of US market on BSESN in future volatility.

Multivariate GARCH process was applied to investigate the bi-directional volatility spillover amongst stocks and returns. Asymmetric BEKK-GARCH was used to inspect the linkage between FBMS Shariah index of Malaysia and the sectoral indices [11]. Mean return spillover effect was observed which contributed a significant part in FBMS. Furthermore, a robust indication of transference of past shocks was found in FBMS index and sectoral indices. In addition to these, [12] examined co-movement of 41 emerging markets of Asia, Europe, Latin America, and the Middle East. Mean spillovers effect was found in emerging Asia and Latin America markets while spillovers effect was observed in variance for the emerging markets of Europe.

Volatility co-movement among the US, UK, Hong Kong and Japan stock exchange was explored by [13]. Granger causality based VAR model was employed to assess the effect of US market on UK, Hong Kong and Japan while BEKK-GARCH was used to study the volatility spillover. It was found that causality of USA and UK are more likely the reason of altering return in Japanese market. Furthermore, US is more sensitive to its own past shock in the catastrophe period.

The dynamics of co-movement between Central and Eastern European (CEF) and developed European (France, the UK, Germany and Austria) markets using a Wavelet approach was studied by [14]. Their result of unconditional correlation showed that developed markets of Europe have more interrelationship than the CEE stock markets. In short, European assimilation causes to increases volatility co-movement between developed markets of Europe and CEF markets. However, financial catastrophes during the study period led to increased co-movements only for short-term.

The organization of the study is as follows. Brief discussion about BEKK- GARCH model is given in Section 2. Empirical analysis and discussion are given in Section 3. Section 4 concludes the paper.

\section{BEKK-GARCH model}

VECH-GARCH model is basic form of multivariate GARCH model which generalizes ' $\mathrm{N}$ ' univarite GARCH models. It is quite difficult to manage a model having a large number of parameters. Therefore, DVECH model imposes constraint of diagonality to lessen the number of parameters developed by [15]. However, both VECH and DVECH models do not guarantee the conditions of positive definite variance-covariance matrix. In 1995, [16] developed BEKK model which imposes the condition of positive definite in the conditional variance matrix $\mathrm{V}_{\mathrm{t}}$ [17]. This BEKK model is flexible as VECH model with constrain of positive definiteness.

Mathematically, BEKK-GARCH model can be expressed as,

$$
V_{t}=C C^{\prime}+\sum_{j=1}^{q} \sum_{s=1}^{S} u_{s j}^{\prime} e_{t-j} e_{t-j}^{\prime} u_{s j}+\sum_{k=1}^{p} \sum_{s=1}^{S} w_{s k}^{\prime} V_{t-k} w_{s k}
$$


Equation 1, represents BEKK-GARCH (p, q) model, C, ' $u$, and ' $w$, are $N \times N$ coefficients matrix. The number of parameter of equation can be obtained from $2 N^{2}+N(N+1) / 2$. Therefore, for two return series $(\mathrm{N}=2)$ with order $(1,1)$ the estimated parameters will be 11 . If there are three return series $(\mathrm{N}=3)$ then the total number of parameters for BEKK-GARCH $(1,1)$ would be 24 . Similarly, as the number of variables increases consequently parameters will increase more rapidly which is difficult to manage and interpret the result. The BEKK-GARCH $(1,1)$ can be defined by the following equation ,

$$
V_{t}=C C^{\prime}+u^{\prime} \tau_{t-1} \tau_{t-1}^{\prime} u+w^{\prime} V_{t-1} w
$$

To reduce the number of parameters in BEKK-GARCH model scalar BEKK and diagonal BEKK were developed. In this study we used three return series therefore the mathematically Diagonal BEKK is descried as,

$$
\begin{aligned}
& {\left[\begin{array}{l}
\vartheta_{11, t} \\
\vartheta_{21, t} \\
\vartheta_{22, t}
\end{array}\right]=\left[\begin{array}{ccc}
c_{11} & 0 & 0 \\
0 & c_{22} & 0 \\
0 & 0 & c_{33}
\end{array}\right]\left[\begin{array}{ccc}
c_{11} & 0 & 0 \\
0 & c_{22} & 0 \\
0 & 0 & c_{33}
\end{array}\right]+\left[\begin{array}{ccc}
u_{11} & 0 & 0 \\
0 & u_{22} & 0 \\
0 & 0 & u_{33}
\end{array}\right]\left[\begin{array}{ccc}
e_{1, t-1}^{2} & e_{1, t-1} e_{2, t-1} & e_{1, t-1} e_{2, t-1} \\
e_{2, t-1} e_{1, t-1} & e_{2, t-1}^{2} & e_{2, t-1} e_{3, t-1} \\
e_{3, t-1} e_{1, t-1} & e_{3, t-1} e_{2, t-1} & e_{3, t-1}^{2}
\end{array}\right]} \\
& {\left[\begin{array}{ccc}
u_{11} & 0 & 0 \\
0 & u_{22} & 0 \\
0 & 0 & u_{33}
\end{array}\right]+\left[\begin{array}{ccc}
w_{11} & 0 & 0 \\
0 & w_{22} & 0 \\
0 & 0 & w_{33}
\end{array}\right]\left[\begin{array}{lll}
\vartheta_{11, t-1}^{2} & \vartheta_{12, t-1} & \vartheta_{12, t-1} \\
\vartheta_{21, t-1} & \vartheta_{22, t-1}^{2} & \vartheta_{23, t-1} \\
\vartheta_{31, t-1} & \vartheta_{32, t-1} & \vartheta_{33, t-1}^{2}
\end{array}\right]\left[\begin{array}{ccc}
w_{11} & 0 & 0 \\
0 & w_{22} & 0 \\
0 & 0 & w_{33}
\end{array}\right]}
\end{aligned}
$$

After simplifying the above matrix form following equations will be obtained.

$$
\begin{aligned}
& \vartheta_{11, t}=c_{11}^{2}+u_{11}^{2} e_{1, t-1}^{2}+w_{11}^{2} \vartheta_{11, t-1}^{2} \\
& \vartheta_{21, t}=u_{11} u_{22} e_{1, t-1} e_{2, t-1}+w_{11} w_{22} \vartheta_{12, t-1} \\
& \vartheta_{22, t}=c_{22}^{2}+u_{22}^{2} e_{2, t-1}^{2}+w_{22}^{2} \vartheta_{22, t-1}^{2} \\
& \vartheta_{31, t}=u_{11} u_{33} e_{3, t-1} e_{1, t-1}+w_{11} w_{33} \vartheta_{13, t-1} \\
& \vartheta_{32, t}=u_{22} u_{33} e_{3, t-1} e_{2, t-1}+w_{33} w_{22} \vartheta_{23, t-1} \\
& \vartheta_{33, t}=c_{33}^{2}+u_{33} e_{3, t-1}^{2}+w_{33}^{2} \vartheta_{33, t-1}^{2}
\end{aligned}
$$

Where $\vartheta_{11, t}, \vartheta_{22, t}$ and $\vartheta_{33, t}$ are conditional variance equation and $\vartheta_{12, t}, \vartheta_{13, t}$ and $\vartheta_{23, t}$ represent conditional covariance equations which satisfy the condition of covariance stationary $u_{j j}^{2}+w_{i i}^{2}<1$.

\section{A. Estimation of the BEKK-model}

The parameters of diagonal BEKK model are estimated via Maximum Likelihood estimation. In this study the $\log$ likelihood function of multivariate normal distribution is defined as;

$$
L_{t}=\ln \left\{g\left(e_{t} \mid F_{t-1}\right)\right\}
$$

$\log L_{t}(\varphi)=-\frac{N \cdot T}{2} \ln (2 \pi)-\frac{\ln \left(\left|\Sigma_{t}\right|\right)}{2}-\frac{\sum_{t=1}^{T} e_{t} \Sigma_{t}^{-1} e_{t}}{2}$

Where $\varphi$ represents the vector of unknown constants, the total number of observation of each return series are represented by ' $T$ '. However, numerical maximization method Berndt- Hall-Hall-Hausman applies to yield the maximum likelihood estimates of the parameters and their corresponding standard errors. 


\section{Empirical analysis}

The data employed are daily indices of three stock markets namely, Pakistan, India and Sri Lanka covering the period $1^{\text {st }}$ January, 2011 to $23^{\text {rd }}$ January, 2019 from www.yahoofinance.com. In multivariate modeling number of observation must be same. In order to make the series equal missing values are addressed by swapping the values of the prior day when the market was open.

Table 1:-Summary of Basic statistics

\begin{tabular}{|l|l|l|l|}
\hline & Dlog(BSESN) & Dlog(CSE) & Dlog (KSE-100) \\
\hline Mean & 0.0003 & -0.0001 & 0.0006 \\
\hline Median & 0.0000 & 0.0000 & 0.0002 \\
\hline Maximum & 0.0370 & 0.0496 & 0.0442 \\
\hline Minimum & -0.0612 & -0.0372 & -0.0477 \\
\hline Std. Dev & 0.0093 & 0.0062 & 0.0092 \\
\hline Skewness & -0.1761 & 0.1901 & -0.3989 \\
\hline Kurtosis & 5.1441 & 9.6432 & 5.9577 \\
\hline Jarque-Bera & 413.7 & 3879.7 & 822.3 \\
\hline Probability & 0.00 & 0.00 & 0.00 \\
\hline
\end{tabular}

Summary of basic statistics for the considered returns series are presented in Table 1. Over the whole sample, KSE100 has the highest average return i.e. $0.026 \%$ while BSESN has $0.03 \%$ and CSE has lowest negative mean return i.e. $-0.01 \%$. Volatility for the selected markets ranges from $0.93 \%$ (India) to $0.62 \%$ (CSE). On contrary, the standard deviation for BSESN (0.93) and KSE-100(0.92) are approximately equal whereas CSE has 0.0062. Therefore, CSE is less fluctuated than BSESN and KSE-100. The measures of skewness and excess kurtosis show that the return series are asymmetric and fat tail exhibit conditional heteroskedasticity as well.

Returns series are non-stationary confirmed by the Jarque-Bera test. Therefore, ADF test is used to make the returns series stationary. The result of ADF test indicates at level log daily share price are non-stationary as the P-value is significant which rejecting null hypothesis (series are non-stationary). Therefore data is stationary at first-difference, Table (2).

Table 2:-output of ADF test

\begin{tabular}{|l|l|l|l|l|l|l|c|}
\hline & \multicolumn{3}{|c|}{ BSESN } & KSE-100 & CSE \\
\hline & & t-Statistic & Prob.* & & Prob.* & t-Statistic & Prob.* \\
\hline ADF-test & Test critical values & -43.0529 & 0 & -39.6467 & 0 & -38.369 & 0 \\
\hline & $1 \%$ level & -3.43326 & & -3.43326 & & -3.43326 & \\
\hline & 5\% level & -2.86271 & & -2.86271 & & -2.86271 & \\
\hline & $10 \%$ level & -2.56744 & & -2.56744 & & -2.56744 & \\
\hline
\end{tabular}

Plots of daily closing prices and returns of selected countries are given below. From Figures 1(b), 2(b), 3(b) returns series display volatility clustering and leverage effects as well. However, KSE-100 appears to be more volatile. Graphical representation and descriptive statistic of returns series confirm heteroskedasticity.

Figure 1:-(a) Daily share price of BSESN

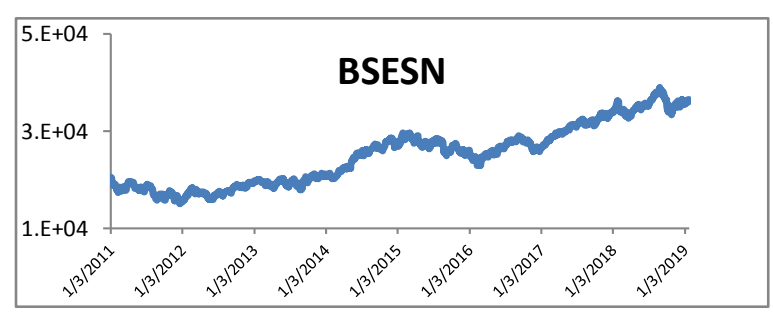

Figure1:-(b) Returns of BSESN

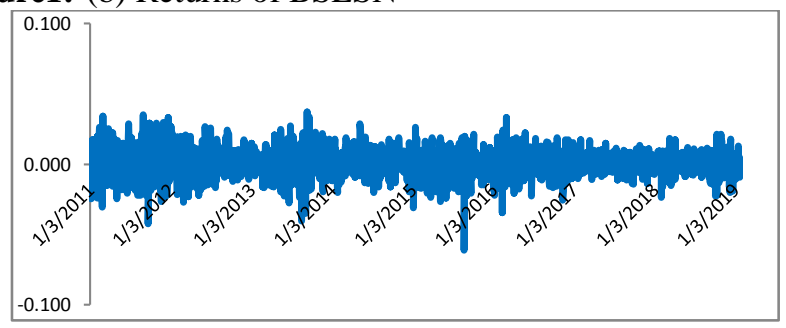


Figure 2:-(a) Daily share price of KSE-100

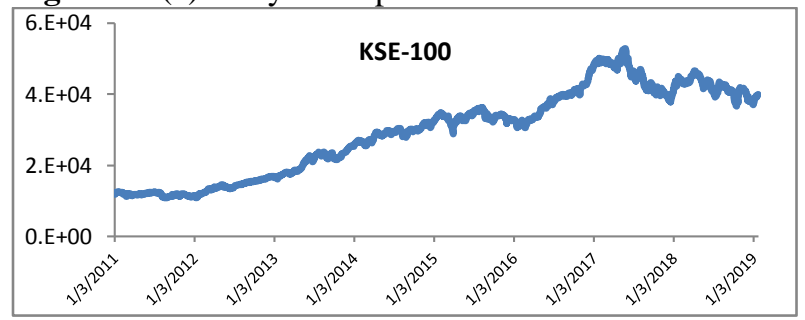

Figure 3:-(a) Daily share price of CSE

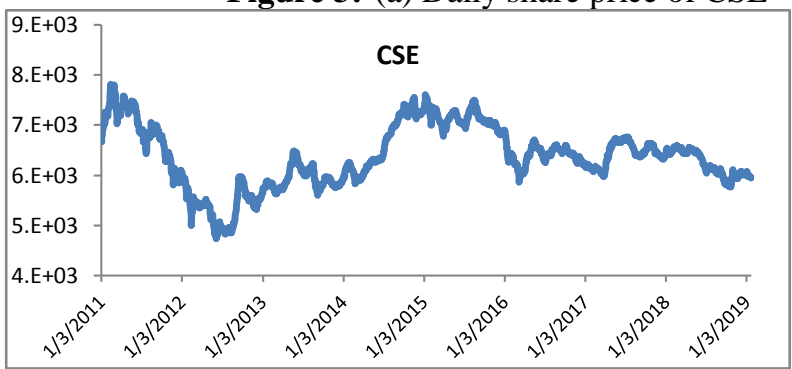

Figure 2:-(b) Returns of KSE-100

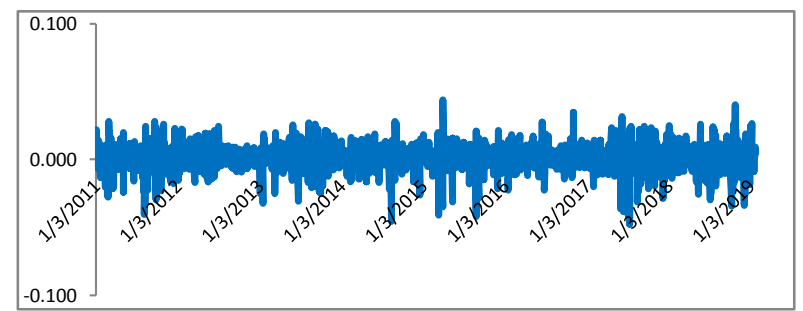

Figure 3:-(b) Returns of CSE

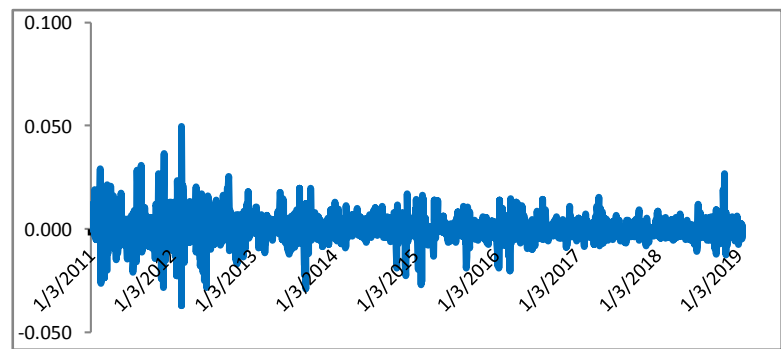

\section{BEKK model estimation}

In this study, Diagonal BEKK-GARCH $(1,1)$ model for the selected stock markets is estimated via method of maximum likelihood using normal distribution. All the estimated parameters are significant as the p-values of the coefficients are less than 0.05 (level of significance), Table 3 . The coefficients of past lagged residual are less than coefficient of the past lagged variance $\left(\left|u_{j j}\right|<\left|w_{i i}\right|\right)$ for all series. This shows that current variance is not highly affected by lagged residuals, lagged variance and lagged covariance.

Among all three markets the parameter ' $w_{i i}$ ' (GARCH effect) is as high as in India (0.96) followed by Sri Lanka (0.87) and minimum in Pakistan (0.82). These results show that Pakistan stock market is less persistence than India and Sri Lanka. However, India is highly persistent, acquires more of its volatility persistence from International market. In addition, the own volatility spillover effects for the stock markets under consideration do not remain within a tight range.

Furthermore, the coefficients of ARCH effects (' $u_{j j}$ ', own-volatility spillovers) in Pakistan (0.11) has higher short term shock effect followed by Sri Lanka (0.1) and India (0.097) has minimum. The highest value of ' $u_{j j}$ ' suggests that the volatility of KSE-100 is highly sensitive for market events but not permanently.

Sum of the coefficients of $\mathrm{ARCH}$ and GARCH are $u_{11}+w_{11}=0.025+0.97=0.99<1$ (India), $u_{22}+w_{22}$ $=0.09+0.826=0.92<1$ (Pakistan) and $u_{33}+w_{33}=0.024+0.97=0.98<1$ (Sri Lanka). This directs that the return series are stationary and the conditional variance is finite.

Table 3:-Estimates of Diagonal BEKK-GARCH $(1,1)$ model

\begin{tabular}{|l|l|l|l|}
\hline & Coefficient & Std. Error & z-Statistic \\
\hline$c_{11}^{2}$ & $7.01 \mathrm{E}-06$ & $8.40 \mathrm{E}-07$ & 8.4 \\
\hline$c_{22}^{2}$ & $8.97 \mathrm{E}-07$ & $1.35 \mathrm{E}-07$ & 6.64 \\
\hline$c_{33}^{2}$ & $5.81 \mathrm{E}-07$ & $1.74 \mathrm{E}-07$ & 3.336 \\
\hline$u_{11}$ & 0.158 & 0.010 & 15.533 \\
\hline$u_{22}$ & 0.312 & 0.016 & 19.739 \\
\hline$u_{33}$ & 0.331 & 0.012 & 27.774 \\
\hline
\end{tabular}




\begin{tabular}{|l|l|l|l|}
\hline$w_{11}$ & 0.984 & 0.002 & 436.458 \\
\hline$w_{22}$ & 0.909 & 0.009 & 105.261 \\
\hline$w_{33}$ & 0.934 & 0.004 & 208.996 \\
\hline
\end{tabular}

In order to study the volatility and volatility co-movement among the selected market the conditional variancecovariances equations are developed by using Diagonal BEKK model. Equation (3)-(8) estimated via Normal.

$$
\begin{aligned}
& \vartheta_{11, t}=5.01 \mathrm{E}-06+0.025 e_{1, t-1}^{2}+0.96 \vartheta_{11, t-1}^{2} \\
& \vartheta_{22, t}=8.9 \mathrm{E}-07+0.09 e_{2, t-1}^{2}+0.82 \vartheta_{22, t-1}^{2} \\
& \vartheta_{33, t}=5.8 \mathrm{E}-07+0.109 e_{3, t-1}^{2}+0.87 \vartheta_{33, t-1}^{2} \\
& \vartheta_{12, t}=0.049 e_{1, t-1} e_{2, t-1}+0.89 \vartheta_{12, t-1} \\
& \vartheta_{13, t}=0.15 e_{3, t-1} e_{1, t-1}+0.84 \vartheta_{13, t-1} \\
& \vartheta_{23, t}=0.103 e_{3, t-1} e_{2, t-1}+0.91 \vartheta_{23, t-1}
\end{aligned}
$$

From the above empirical results a robust indication of GARCH effect and presence of a weak ARCH effects are observed in all return series. However, the equations (6) to (7) represent volatility co-movemnet (covariance). The past common information to the present effect is represented by ARCH coefficients. Whereas, the persistence concerning the covariance and their return volatility is denoted by GARCH coefficient. The high value of ARCH coefficient (cross-market effect $=0.15$ ) is observed between Pakistan and Sri Lanka stock markets. This shows that the past information will affect from Pakistan to Sri Lanka. On the other hand, low value of ARCH effect (0.049) is found between Pakistan to India.

In case of India cross-volatility persistence varies from 0.89 (Pakistan) to 0.84 (Sri Lanka). Nevertheless, the cross volatility from Pakistan to Sri Lanka fluctuates 0.91 . Therefore, in terms of cross-volatility persistence the least influential market is Sri Lanka whereas high influential market is Pakistan.

\section{Diagnostics test of BEKK model:}

It is important to test whether the estimated model is adequate and no $\mathrm{ARCH} / \mathrm{GARCH}$ effects left in the residuals series. If there are unexplained effects left seems that the fitted model represents the sample poorly. The Lagrange Multiplier(LM) test for standardized residuals is employed. Table 3, presents the result of ARCH-LM for each standardized residuals series of the BEKK-GARCH $(1,1)$. The P-values of all lags are greater than at $5 \%$ level of significance, accept null hypothesis that no GARCH effect is left in the estimated model. This seems BEKKGARCH $(1,1)$ model better deals with the GARCH effects.

Table 3:-ARCH-LM test of each standardized residuals of the BEKK-GARCH $(1,1)$

\begin{tabular}{|l|l|l|l|l|l|l|}
\hline & \multicolumn{2}{|l|}{ BSESN } & KSE-100 & \multicolumn{2}{l|}{ CSE } \\
\hline Lag & LM & P-value & LM & P-value & LM & P-value \\
\hline 1 & 1.77 & 0.183 & 0.219 & 0.64 & 1.7 & 0.19 \\
\hline 2 & 3.13 & 0.21 & 0.42 & 0.81 & 1.9 & 0.37 \\
\hline 3 & 3.27 & 0.35 & 0.43 & 0.93 & 2 & 0.57 \\
\hline 4 & 3.93 & 0.416 & 3.3 & 0.51 & 2.9 & 0.56 \\
\hline 5 & 4.1 & 0.53 & 3.5 & 0.61 & 3.01 & 0.69 \\
\hline
\end{tabular}

The plot of estimated conditional variance of the considered stock markets via Diagonal BEKK-GARCH model is illustrated below. 
Figure 4:-Graph of estimated conditional volatility of Diagonal BEKK-GARCH $(1,1)$ model

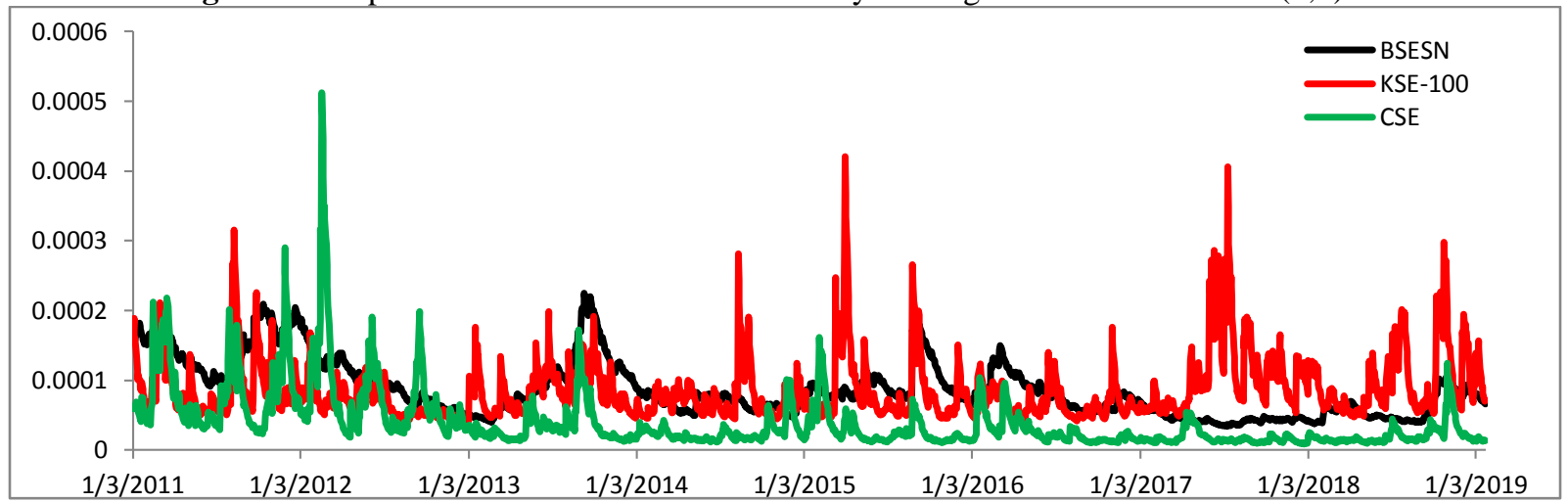

Figure 4, visualizes that no one of the selected returns have oblige extreme conditional volatility. Nevertheless, KSE-100 is highly fluctuated as compared to BSESN and CSE. Specially, from August, 2014 to end of August, 2015, and April, 2017 to till date are observed turmoil periods for KSE-100. Additionally, on $1^{\text {st }}$ April, 2015 it attains maximum peaked value i.e. 4.2E-04. Besides this, highest volatility period for CSE is observed from May, 2011 to September, 2012. Furthermore, during this period it also touches on highest conditional volatility i.e. 4.24E04 on $17^{\text {th }}$ February, 2012. Moreover, the estimated conditional volatility moves with low fluctuation while BSESN moves steadily.

Figure 5:-Graph of conditional covariance of BEKK-GARCH $(1,1)$.

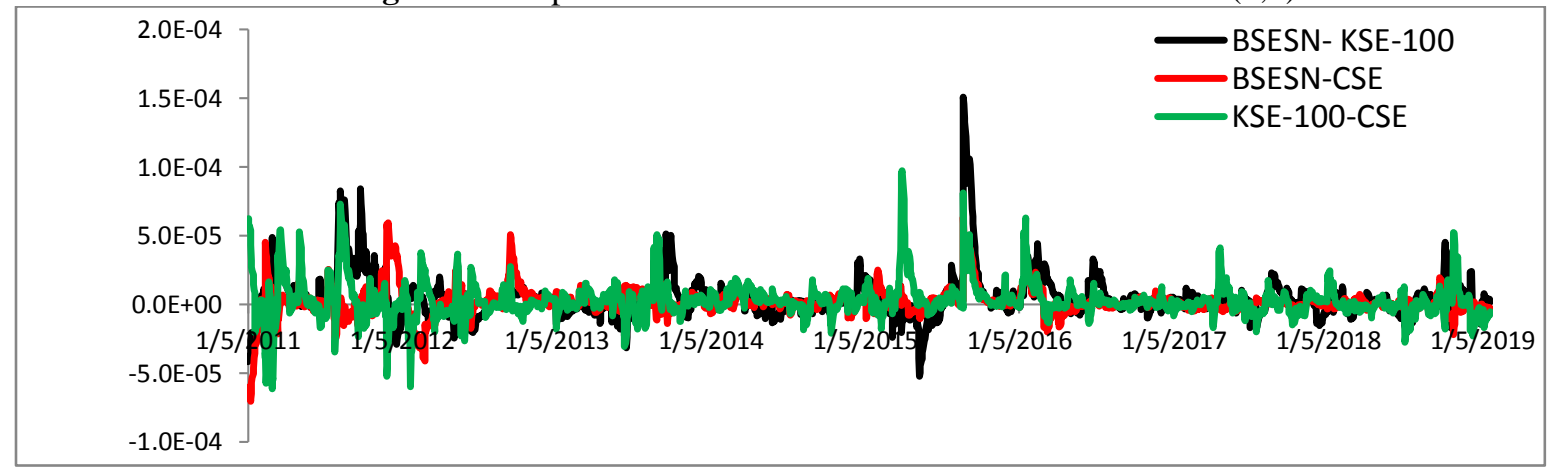

Figure 5, displays estimated conditional covariances of BEKK-GARCH $(1,1)$ model of BSESN, KSE-100 and CSE. The conditional covariances for selected returns series are plotted, none of the series move abruptly. The conditional covariance between KSE-100-BSESN depicts few prominent spikes than other pair of conditional covariance shows cross-volatility KSE-100 to BSESN is little bit higher during 2011-2012.

\section{Conclusion:-}

This study inspects the dynamics of volatility among Pakistan, India and Sri Lanka stock markets. Furthermore, cross-market effects and cross-market covariance effects are also measured among the selected markets via BEKKGARCH(1,1) using daily closing indices from January, 2011 to January 2019. The results of this study can be important for the international investor, portfolio diversification and risk management. Empirical analysis shows that Pakistan stock market is more sensitive to the prior market information due to high value of ARCH coefficient i.e. 0.11. On contrary, the long term volatility is high in BSESN i.e. 0.96 which shows Indian market is more persistence. The strongest cross-market effect is perceived between India and Sri Lanka. On the contrary, the crossmarket covariance is high between Pakistan and Sri Lanka. 


\section{References:-}

1. Henry, P. B. (2000). Do stock market liberalizations cause investment booms?. Journal of Financial economics, 58(1-2), 301-334.

2. Bae, K. H., \& Karolyi, G. A. (1994). Good news, bad news and international spillovers of stock return volatility between Japan and the US. Pacific-Basin Finance Journal, 2(4), 405-438.

3. Lin, W. L., Engle, R. F., \& Ito, T. (1994). Do bulls and bears move across borders? International transmission of stock returns and volatility. Review of financial studies, 7(3), 507-538.

4. Greenidge, K., \& Grosvenor, T. (2010). FORECASTING NON-PERFORMING LOANS IN BARBADOS. Journal of Business, Finance \& Economics in Emerging Economies, 5(1).

5. Sariannidis, N., Galyfianakis, G., \& Drimbetas, E. (2015). The effect of financial and macroeconomic factors on the oil market. International Journal of Energy Economics and Policy, 5(4), 1084-1091.

6. Xiao, L., \& Dhesi, G. (2010). Volatility spillover and time-varying conditional correlation between the European and US stock markets. Global Economy and Finance Journal, 3(2), 148-164.

7. Fiszeder, P., \& Orzeszko, W. (2012). Nonparametric Verification of GARCH-Class Models for Selected Polish Exchange Rates and Stock Indices. Finance A Uver: Czech Journal of Economics \& Finance, 62(5).

8. Kumar, M. (2013). Returns and volatility spillover between stock prices and exchange rates: Empirical evidence from IBSA countries. International Journal of Emerging Markets, 8(2), 108-128.

9. Diebold, F. X., \& Yilmaz, K. (2009). Measuring financial asset return and volatility spillovers, with application to global equity markets. The Economic Journal, 119(534), 158-171.

10. Prashant, J. (2014). Volatility Interactions among India and US Stock Markets. Case Studies in Business and Management, 1(1), 107-117.

11. Ng, S. L., Chin, W. C., \& Chong, L. L. (2017). Multivariate market risk evaluation between Malaysian Islamic stock index and sectoral indices. Borsa Istanbul Review, 17(1), 49-61.

12. Beirne, J., Caporale, G. M., Schulze-Ghattas, M., \& Spagnolo, N. (2010). Global and regional spillovers in emerging stock markets: A multivariate GARCH-in-mean analysis. Emerging markets review, 11(3), $250-260$.

13. Liu, C. (2016). Spillover effects in major equity markets: A GARCH BEKK approach. Open Access Library Journal, 3(02), 1.

14. Dajcman, S., Festic, M., \& Kavkler, A. (2012). Comovement dynamics between Central and Eastern European and developed European stock markets during European integration and amid financial crises-a wavelet analysis. Engineering Economics, 23(1), 22-32.

15. Bollerslev, T., Engle, R. F., \& Wooldridge, J. M. (1988). A capital asset pricing model with time-varying covariances. Journal of political Economy, 96(1), 116-131.

16. Engle, R. F., \& Kroner, K. F. (1995). Multivariate simultaneous generalized ARCH. Econometric theory, 11(1), 122-150.

17. Bauwens, L., Laurent, S., \& Rombouts, J. V. (2006). Multivariate GARCH models: a survey. Journal of applied econometrics, 21(1), 79-109. 